\title{
Medico-legal Institute: A Need of State
}

\author{
Binay Kumar ${ }^{1}$, Avinash Kumar ${ }^{2}$, Vinita Kumari $^{3}$, Ashok Rastogi ${ }^{4}$, Himanshi $^{5}$ \\ ${ }^{1}$ Additional Professor, ${ }^{2}$ Senior Resident, Department of Forensic Medicine \& Toxicology, AIIMS, Patna, \\ ${ }^{3}$ Senior Medical Officer, Central Reserve Police Force, Government of India, ${ }^{4}$ Assistant Professor, ${ }^{5}$ Junior Resident \\ Academic, Department of Forensic Medicine \& Toxicology, AIIMS, Patna
}

\begin{abstract}
Medico-legal Institute have been in existence for centuries in several countries of the world. The importance of setting up of Medico-legal Institute in every state of countries, closely associated with medical colleges, for the systematic teaching of forensic medicine, training of specialists, for the investigation of Medicolegal problems, etc., has been stressed by all the leading medical jurists of the world.The Health Survey and Development Committee (The Bhore Committee) Government of India, 1946, in their report had recommended the starting of Central Medico-legal Institute. Later, Government of India, Ministry of Health and Family Welfare constituted a central Medico-legal Advisory Committee in year 1958, which gave its reportin 1964 and recommendedevery state for establishment of such Medico-legal Institute. The recommendation has been followed very lightly by establishing the Medico-legal Institute in few states only. Now aday due to advancement of technologies and public awareness, Medico-legal issues are increasing days by day. It is the demand of the time to take a solid step to solve these cases in legal and scientific ways. Initiatives of establishment of medico-legal institute in every state can be one of the firm milestones for the settlements of the maximum Medico-legal cases. As Government of India is in the process to establish All India Institute of Medical sciences (AIIMS), in every state in which lands, buildings and manpower has already been planned, so up-gradation of Department of Forensic Medicine and Toxicology of every AIIMS to the level of Medico-legal Institute will be an appropriate decision for reduction of monetary investment.
\end{abstract}

Keywords: Medico-legal, Medical colleges, Advisory Committee, State, AIIMS, Monetary

\section{Introduction}

This century demands, yet obliges, for a rapid and efficient responsive organization. Indeed, imposes for a knowledgeable worker who is highly qualified, innovative and can work autonomously plus in teamwork.Though, globalization is well recognized as a market phenomenon, it is not so far to find a specific service offered by the medico-legal institute. "To deal with global competition, employees have to be able to

\section{Corresponding author: \\ Dr. Binay Kumar}

Additional Professor, All India Institute of Medical

Sciences, Patna. Add: - Flat No. 111, Block-2, Type-4, AIIMS, Patna, residential Complex, PO: - Khagaul, PS:

- Phulwarisharif, Distt: - Patna. PIN: - 801105

Email : dr.binay_rimsranchi@yahoo.co.in keep up with knowledge and new ideas to stay in the race" ${ }^{(1)}$

Medico-legal Institute have been in existence for centuries in several countries of the world. The First Medico-legal institute was started in Austria in 1804. There are medico-legal institutes in Italy, France, Austria, Rumania, Egypt, Japan and other countries.In European Countries like Denmark, Rumania etc., State Medical Officers, even as early as 1914, had to undergo a course of one year in Forensic Medicine in a Medicolegal Institute and obtain a diploma before they were entertained into service.Whereas in India, only one medico-legal institute could be established that too in 1977 by the Government of Madhya Pradesh in Bhopal. According to Prof. Minovici (1928) "in this way the creation of a select body will be attained to which justice will have to address itself exclusively for the opinions in legal medicine". Sothe importance of setting up of 
Medico-legal Institute in every state of countries, closely associated with medical colleges, for the systematic teaching of forensic medicine, training of specialists, for the investigation of Medico-legal problems, etc., has been stressed by all the leading medical jurists of the world.

The Health Survey and Development Ccommittee (The Bhore Committee), Government of India, 1946, in their report had recommended the starting of Central Medico-legal Institute. Later, the Government of India Health Ministry constituted a central Medico legal advisory committee in year 1958. Main function of the committee was to advise the central and state government on matters pertaining to medico legal procedure and practices throughout India and to promote the development of new and modern techniques in the field. The committee gives its report in 1964. Not much concrete work, was, however, done in this direction and subsequently the standing committee on forensic medicine was constituted in the Ministry of Home Affairs to pick up the threads left by the advisory committee report. The committee also observed most regretfully that the medico-legal practices throughout the length and breadth of the country has been found to be in most deplorable condition for the following reasons:

1. Shortage of trend personnel in the profession

2. Absence of even ordinary facilities i.e. transportation cold storage, mortuary, instruments etc. for the practice of the profession.

3. Absence of any incentive for the practitioner to take interest in the so-called dirty work. However provision incentive has been made but only in few states.

4. Want of literature, standard and research on the subject with an Indian bias, which is veryimportant as in many cases. ${ }^{(2)}$

Consequently suspects may not get fair and it is possible that criminals may escape or innocent convicted.

The Survey Committee believes that each state should also start a State Medico-legal Institute at its capital city attached to Medical College. The central Medico-legal Advisory Committee during its sixth session recommended that the Union Government should sanction substantial aid in the form of grants, equipments for the institute, fellowship etc. ${ }^{(3)}$

The Committee feels that the Department of Forensic Medicine should have access or be given a share in part of the work of the Casualty Department of a teaching Hospital and the Professor of Forensic Medicine be designated as Consultant in Clinical Forensic Medicine.

Although Medico-legal practice is purely a medical subject and practiced only by graduates of Medicine, so, the Committee also recommended that the medicolegal practitionershould remain under Ministry of Health rather than under Ministry of Home \& Law as if that the incumbents should in no sense be dependent upon departments which are concerned with the process of trial or the investigation of crime.

\section{Present Position of Medico-legal Service in India}

The present position in regard to the investigation of medico-legal problems is very unsatisfactory. Every medical practitioner in charge of a remote dispensary whatever his qualification or experience, is asked to undertake medico-legal post-mortem in complicated cases of crime and he is liable to be held in question thereafter, the presumption being that every medical man is competent to undertake these responsibilities, but unfortunately neither the profession nor the judiciary nor the State have stopped to consider the absurdity of such a presumption.

The improper performance of an autopsy, and failure to understand the normal from pathological findings and their misinterpretation have frequently resulted in miscarriage of justice. Further, scrutiny of medico-legal certificates at random in several States has revealed very poor quality of medico-legal work resulting mostly from ignorance and occasionally from indifference.

In India the participation of medical officer in the investigation of crime is often restricted only to the performance of a post-mortem examination. Inspection of the body at the scene of crime is most essential to a proper medico-legal autopsy. It is regretted that the present system is defective in this respect as it is not practicable for the medical officer to visit the scene of crime due to lack of funds, security, manpower, vehicles $\&$ other logistics and has to depend on the police requisition or inquest report. 
It is noticed that many specimens for toxicological analysis are being sent by medical officers without any scientific indication or necessity for such an examination; this is largely due to their lack of knowledge of pathology. Similarly the investigating police officers also are observed to collect far too many specimens of bloodstains, etc., in some cases which do not warrant such a procedure.

\section{Background}

According to data on conviction rate for 2014, collated by National Crime Records Bureau (NCRB) and presented by the government in Parliament, the percentage of cases in which the accused received punishment stood at over 45\%. In 2013, the same figure was $40.2 \%$ while in 2012 it stood at $38.5 \%$.

In 2014, Kerala was the best performing state with over $77 \%$ convictions while Bihar was the worst with just $10 \%$.

The trend is significant as since independence conviction rate in cognisable crime (offences which fall under Indian Penal Code) have been consistently falling. The oldest record in this respect is that of 1953 , the year when NCRB began collating crime data. In that year, the percentage rate of conviction to total cases tried was almost $64 \%$.In the next decade it improved to $65 \%$. However, 70 s onwards it has been consistently declining, dropping to less than $40 \%$ in 2012 .

Even Uttar Pradesh, with its infamous lawlessness, does better than the national average clocking 53.2\%. Bihar is the worst with $10 \%$ conviction rate followed by West Bengal where the figure is $11 \%$. Maharashtra, which not too long ago had one of the worst conviction rates hovering at $6-7 \%$ has shown marked improvement clocking a rate of $19.3 \%$ in 2014. In 2013, the figure for Maharashtra was $13 \%$ while in 2012 it was just $9 \% .{ }^{(4)}$

Over the years, the national capital has fast emerged as the crime capital of the country. And while an overburdened Delhi Police claims it is doing its best to reduce crime, the conviction rate tells a different story.

Rates of conviction in Delhi have been steadily falling over the last 12 years. While in 2005, 31.2 per cent of cases registered resulted in convictions, it fell drastically in 2016 to a paltry 4.9 per cent, according to information from the Ministry of Home Affairs (MHA). ${ }^{(5)}$

\begin{tabular}{|c|c|c|}
\hline \multicolumn{2}{|c|}{ National Crime Records Bureau (NCRB) } \\
\hline Year & Total Cases registered & Conviction \\
\hline 2012 & 54287 & 28.7 \\
\hline 2013 & 80184 & 14 \\
\hline 2014 & 155654 & 7.3 \\
\hline 2015 & 191377 & 5.1 \\
\hline 2016 & 209519 & 4.9 \\
\hline
\end{tabular}

According to NCRB top reasons for low conviction rate are

1. Hostile witness

2. Long duration of trial 
3. Faulty investigation

In 2016, one in four rape cases in India ended in conviction - lowest since 2012-according to national crime data.

India's conviction rate for rape, at $25.5 \%$, remains low compared to all cognisable crimes - those that do not require a magistrate's permission to investigate under the Indian Penal Code (46.9\% in 2015).
Nagaland (72.7\%) and Mizoram (70.6\%) had the best conviction rates in 2015 - the year for which latest data were available - while Jammu and Kashmir (7\%) and Gujarat (10.1\%) had the worst.

As many as 278,886 rape cases have been reported in India over the last 10 years under Section 376 of the Indian Penal Code. ${ }^{(6)}$

India's Rape Conviction Rate, 2007-16

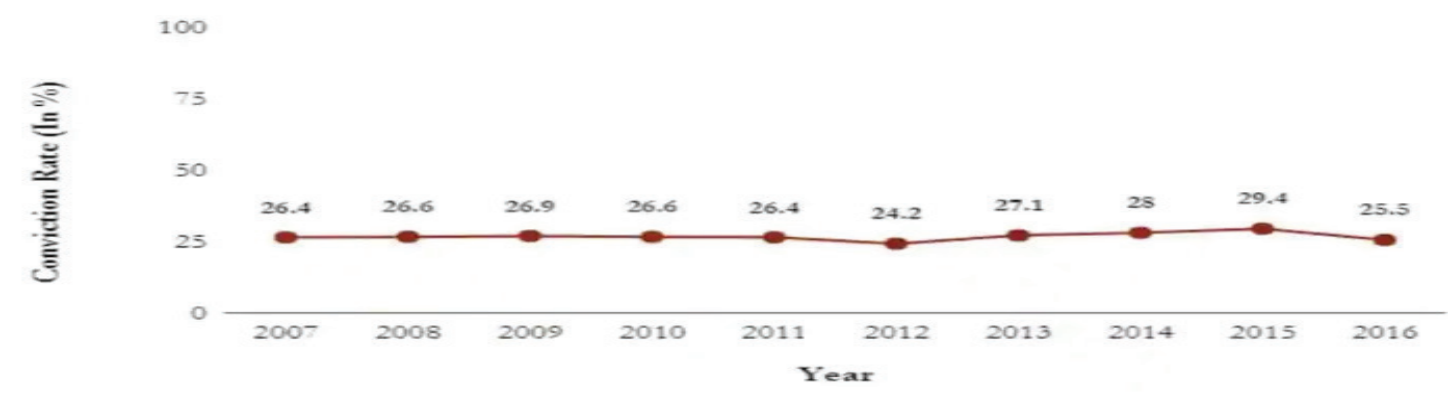

Source: National Crime Records Bureau, Lok Sabha NOTE: Date for 2016 are provisional.

\section{Cause of low conviction rate in India}

1. No witness protection program -

India doesn't have a state sponsored witness protection program. Witnesses often turn hostile because of this.

2. Police not well trained and equipped-

The Police officials in India are poorly equipped. A lot of Police work is still done manually. Police official aren't trained to use computers and lack the necessary knowledge of both science and sadly even law.

\section{Lack of training Institute-}

India has lack of medico-legal institute in which the police officials and other scientific persons can be trained for collection and preservation of evidences of different crimes. Forensic laboratories

India doesn't have well equipped laboratories and training centers in all the states. DNA and other forensic data has to be sent to forensic laboratories and that involves a lot of protocols as well as time. Also, lack of state medico-legal institute leads to large consumption of time for the chain of custody of the evidences.

4. Witnesses turning hostile

Sadly, this seems to be a major reason of low conviction rate in rape cases in India. A lot of times, the victims know the Accused. They either turn hostile owing to threats or settle outside the court.

\section{Functions \& Duties of Medico-legal Institute}

The following functions should be carried out by the Medico-legal institute in collaboration with Medical College:

i. To cater to the needs of undergraduate and postgraduate education in forensic medicineand to provide appropriate courses of instruction to other lawenforcing agencies

ii. Be responsible for conduct of all medico legal Necropsies of the city and the autopsiesfrom the various district of the State and to give an opinion in expert opinion casesfrom whole state in medico legal cases. 
iii. Undertake medico legal examination of skeletal remains

iv. Be responsible for all forensic serological investigations of the state

v. To provide consultative service to medical officers and guide those engaged in clinicalforensic medicine practice;

vi. To work in close collaboration with the departments of police and Justice (law) whom it should provide consultative and advisory services on all relevant technicalproblems concerning investigation of crime. It should also advise the Government onall Medico legal matters;

vii. To conduct research

viii. To establish the advanced toxicology lab and hospital ward, OPD, procedure room etc to provide high level of patient care for poisoning cases.

Laboratories in the institute

- Anthropology

- Entomology

- Histopathology

- Photography

- Mortuary services

- Toxicology and Chemical analysis

- forensic psychiatry

- forensic odontology

- Forensic Radiology

- Forensic Serology

- Poison information center

Power and duties that can be conducted employees of Medico-legal institute in collaboration with Medical College.

1. The main function of Institute is to conduct all autopsies of the city and also the autopsies referredfrom various district of state
2. To give expert opinion in the medico-legal cases referred from whole state.

3. In addition during routine investigation relating viscera Analysis, Diatom, Vaginal smear,entomology are alsoconducted.

4. Quality FSL work given to theInstitute.

5. In complicated cases the technique of investigative and reconstructive forensic medicine can also be used.

6. Crime Scene visit.

7. Medical and medico-legal management of poisoning cases.

Useful Scheme for a common man

The most important hypothesis of the Institute lies on the fact that "Dead never speaks lie while living persons may speak lie" However the deceased person has low voice, but he need a full satisfaction and faith that he is to be listen sincerely and seriously. In this world there is always a scientific reason behind every phenomenon rather it is being considered as a wonder.

1. The important functions of Medico-legal Institute should be very specific and continue to be for the common man utility. The Institute should render scientific opinion in the police cases, which are being referred from the entire state particularly where there is difference of opinion in suspicious death events or common public/aggrieved party is not satisfied with the police investigation and doctor's opinion. Accordingly when these cases have been referred to the Institute usually the body is not available, only one the basis of documents viz. postmortem report, Panchnama, Morg Information, F.I.R., clothings and Photographs of Scene of Crime etc. The Institute should draw scientific appraisal coordinating the facts mentioned in the above documents among each other and his supporting evidence. Thus a justified opinion is being given in each case.

2. In Medical negligence cases, if the cases are referred to medico-legal institute situated in Medical College, the condition and situation can be better understand by the doctors, and better opinion and judgment can be given for the doctors and the patient. 
3. In Forensic Toxicology, the institute can give immediate result of poison which will help in diagnosis and treatment of patient of suspected poisoning case. It will further help the judiciary in medico-legal autopsy by diagnosing the suspected death due to overdose of drugs or poisoning in very less time, which is time consumable due to maintaining chain of custody.

4. The institute can serve the public by visiting and collecting the evidence from the scene of crime in more scientific way.

5. The Institute can serve the society by organizing regularly the training courses for Doctors, Police and Judicial personnel on the important Medico-legal issues.

6. This will also help the department follow up the regulations like maintaining the medico-legal records of all cases for at least 30 years.

\section{Discussion}

The one important single factor in the stalemate in the medico-legal practice in our country is the lack of Medico-legal Institutes or full-time Departments of Forensic Medicine in Medical Colleges imparting postgraduate training in Forensic Medicine. This has resulted in the paucity of regularly qualified experts. The work has been carried on by "untrained or ill-trained" State Medical Officers. It should be emphasized that forensic medicine is as much a specialty as any specialised branch in medicine or surgery and medico-legal work cannot be lightly thrown on the shoulders of any every medical man. The fact that all medical jurists in the United Kingdom are experienced forensic pathologists might be followed in India with advantage.

Across the state, medical colleges have forensic medicine departments, but do not have a dedicated center for medico-legal cases. Medico-legal institute in Medical College will provide a better platform for the medico-legal work beneficial for both the dead and alive patients. The establishment and successful functioning of the Medico-legal Institute can be fulfilled in better ways when it is established in Medical Colleges, as it will provide construction space, qualified man-power, working environment and case availability.

Although inefficiency in medico-legal practice is in no way directly responsible for the increase in crime figures yet a well organised and efficient medico-legal service is indispensable for the proper investigation and trial of all crime cases which would have a deterrent effect on the criminals and make them realise that science does not permit crime to pay.

In spite of recommendation of various committees to establish Medico-Legal Institute in every state, it could only be established only in one state. However ray of hope is Government of India has planned to establish AIIMS in every state for which financial provision is being done for more than ten thousand millions rupees for each AIIMS. If Government can provide ten thousand million then it can also provide eleven thousand million to upgrade the Forensic Medicine \& Toxicology department to the level of Medico-legal Insitute.

\section{Conclusion}

Now days due to advancement of technologies and public awareness, Medico-legal issues are increasing days by day, it is the demand of the time to take a solid step to solve these cases in legal and scientific ways. Initiatives of establishment of medico-legal institute in every state can be one of the firm milestones for the settlements of the maximum Medico-legal cases. The recommendation by different committee constituted by Government of India has been followed very lightly by establishing the Medico-legal Institute in few states only. As Government of India is in the process to establish All India Institute of Medical sciences (AIIMS), in every state in which lands, buildings and manpower has already been planned, so up-gradation of Department of Forensic Medicine and Toxicology of every AIIMS to the level of Medico-legal Institute will be an appropriate decision for reduction of monetary investment.

Conflict of Interest: - None

Source of Funding: - Not required

Ethical clearance: - NA

\section{References}

1. Wilpert B. Impact of globalization on human work. Safety Science [Internet]. 2009 Jul [cited 2021 Feb 17];47(6):727-32. Available from: https://linkinghub.elsevier.com/retrieve/pii/ S0925753508000258 
2. Right to Information Act 2005 - CHAPTER II 4 (B) I TO XVII. Gazette of India no 22 of 2005; 2005.

3. Services IDG of H. Survey Committee Report on Medico-legal Practices in India, 1964. Manager of Publications; 1964. 90 p.

4. KM A. What NCRB statistics says about Criminal Justice system in India? LiveLaw.in [Internet]. 2015 Nov 13 [cited 2021 Feb 17]; Available from: https://www.livelaw.in/what-ncrb-statistics-saysabout-criminal-justice-system-in-india/

5. Sharma A. Conviction rate in Delhi at all-time lowThe New Indian Express. The New Indian Express
[Internet]. The Sunday Standard. 2018 Jan 6 [cited 2021 Feb 17]; Available from: https://www. newindianexpress.com/thesundaystandard/2018/ jan/06/conviction-rate-in-delhi-at-all-timelow-1746522.html

6. Mallapur C. Only one in four rape cases in India ended in conviction in 2016 | Hindustan Times. Hindustan Times [Internet]. India News. 2017 Aug 28 [cited 2021 Feb 17]; Available from: https:// www.hindustantimes.com/india-news/only-onein-four-rape-cases-in-india-ended-in-convictionin-2016/story-uf7hLwGXubHM0hZRU3ZxxI. html 